\title{
Endogenous antioxidant defenses in malaria comorbidly occurring with typhoid
}

\author{
O. Ademuyiwa, ${ }^{a}$ D. A. Ojo, ${ }^{\mathrm{b}}$ R. N. Ugbaja, ${ }^{\mathrm{a}}{ }^{\text {S. O. }}$. Rotimi ${ }^{\mathrm{c}}$ \\ ${ }^{a}$ Department of Biochemistry, Federal University of Agriculture, Abeokuta, Nigeria \\ ${ }^{b}$ Department of Microbiology, Federal University of Agriculture, Abeokuta, Nigeria \\ 'Department of Biological Sciences, Covenant University, Canaan Land, Ota, Nigeria
}

Submission Date: 28-10-2012; Review Completed: 1-12-2012; Accepted Date: 17-12-2012

\begin{abstract}
Introduction: Malaria and typhoid are two diseases of public health importance that are associated with fever in the tropics. Objective: To assess antioxidant responses during malaria, typhoid and typhoid + malaria infections, the activities of glutathione transferase (GST), catalase (CAT) and the concentrations of glutathione (GST). Materials and Methods: Spectrophometric techniques were used to assay for the biomarkers of oxidative stress in plasma and erythrocytes of patients in Abeokuta, Nigeria $(\mathrm{n}=115)$. Result: The presence of either or both parasitic infections resulted in significant alterations in the antioxidant response of the subjects $(p<0.05)$. Depletion of erythrocyte GSH, increase in plasma GSH and increased expression of CAT in both plasma and erythrocyte, characterized the antioxidant response of the subjects. While the highest erythrocyte CAT activity was observed in typhoid-infected males, the highest plasma CAT activity was observed in females infected with typhoid $(\mathrm{p}<0.05)$. GST activity in malaria infection was not significantly different from control ( $\mathrm{p}$ $>0.05$ ), whereas the activity of the enzyme reduced in typhoid infection and increased when typhoid and malaria infections were present $(\mathrm{p}<0.05)$. Conclusion: Our findings indicate that sex differences might play a significant role in the antioxidant response of subjects in typhoid infection.
\end{abstract}

Keywords: Antioxidant defense, Malaria, Typhoid, Typhoid + Malaria, Sex difference.

\section{INTRODUCTION}

Parasitic protozoa and bacteria infections are responsible for some of the most devastating and prevalent diseases of human worldwide. Among the many parasitic infections, malaria stands out as the most significant human parasitic disease. It remains an important cause of morbidity and mortality in the tropical world. Over 500 million episodes of clinical malaria occur annually, with up to 2.7 million deaths. ${ }^{[1-3]}$

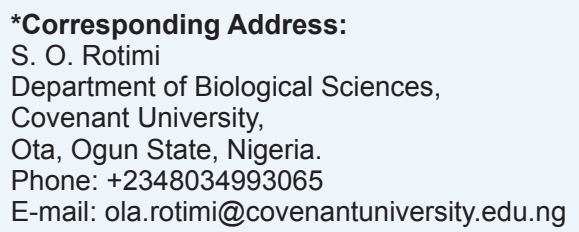

DOI: $10.5530 / a x .2012 .4 .2$
Typhoid fever, another human parasitic disease, is an acute generalized infection of the reticulo-endothelial system. It is a food and water-borne disease caused by Salmonella enterica subspecies enterica serotype Typhi (Salmonella typhi). ${ }^{[4]}$ It is a serious public health problem in developing countries, causing an estimated 16 million illnesses and 600,000 deaths worldwide each year. ${ }^{[5]}$ Both malaria and typhoid fevers are endemic in Nigeria. ${ }^{[6]}$

Recent studies indicate that malaria parasites induce an oxidant stress on the host erythrocytes during malarial infection..$^{[1,7-10]}$ The mechanism and extent of this oxidant stress have attracted the attention of many workers. This altered redox metabolism at the level of the host cell may contribute to disease manifestations and enhanced oxidative stress on erythrocytes may contribute to hemolysis and anaemia observed during malarial infection. Oxidative stress might also play a key role in many of the fatal end points of these parasitic infections. ${ }^{[1]}$ 


\section{O. Ademuyiwa, et al.: Endogenous antioxidant defenses in malaria comorbidly occurring with typhoid}

Typhoid fever, although well recognized as being extremely diverse in its clinical presentation, has overlapping signs and symptoms with malaria, the most prominent being fever. ${ }^{[1]}$ Apart from this, little is known about the biochemical changes induced in the host during typhoid infection. Whether oxidative stress is induced in the host as a result of typhoid infection, is largely unknown. Based on the mounting evidence that oxidative stress might be an important clinical and pathobiochemical factor as well as an effective therapeutic principle in disease conditions, we attempted in this study to characterize the profiles of antioxidant response produced in plasma and erythrocytes of patients suffering from malaria, typhoid and typhoid + malaria by determining the activities of catalase (CAT) and glutathione transferase (GST) and the concentrations of glutathione (GSH).

\section{MATERIALS AND METHODS}

\section{Subjects}

Patients $(\mathrm{n}=115)$, age ranging between 12 and 46 years, presenting at the out-patient clinic of Federal Medical Centre, Abeokuta, Nigeria, with diagnosis of falciparum malaria, typhoid and typhoid + malaria, infections, were recruited for this study. Informed consent was obtained from patients or their relatives. The study was approved by the Ethical Committee of Federal Medical Centre, Abeokuta, Nigeria. Control subjects $(n=24)$ who were staff and students of University of Agriculture, Abeokuta, Nigeria, were recruited in the study at the same period with the patients. Table 1 summarizes the study population.

\section{Methods}

\section{Sample collection}

Venous blood samples were collected from the subjects in heparin before treatment with anti-malarial and antityphoid drugs. Thin and thick blood films were prepared from these samples for malaria microscopy. Routine hematology was also performed on the blood samples. Samples were separated within one hour into plasma and red blood cells. The red blood cells were washed twice

Table 1 Study population

\begin{tabular}{lcc}
\hline Subject & Male & Female \\
\hline Control & 12 & 12 \\
Malaria & 20 & 22 \\
Typhoid & 21 & 22 \\
Typhoid + Malaria & 20 & 10 \\
\hline
\end{tabular}

with $0.9 \%$ saline solution. Aliquots of samples for CAT measurement were stored at $4^{\circ} \mathrm{C}$ while the remaining samples were stored at $-30^{\circ} \mathrm{C}$ until analyzed for GSH and GST.

\section{Malaria status}

From the venous blood samples, thick and thin blood films were prepared. Thick films were air-dried and stained using Field's stain A and B and 50 oil-immersion fields were examined. Thin films were stained with Giemsa stain. P. falciparum malaria parasitemia per $\mu \mathrm{l}$ was determined from thick films by counting parasites per 200 leucocytes, assuming 6000 leucocytes per $\mu .^{[12]}$

\section{Typhoid status}

Widal test was used to determine the presence or absence of typhoid fever. The assay was performed using tube agglutination method by testing the stained antigen against unknown serum serially diluted. ${ }^{[13-15]}$ The presence or absence of visible agglutination was related with the presence or absence of the corresponding homologous antibody. A widal bacteria suspension kit (Cromatest, Linear Chemicals, Montgat, Barcelona, Spain) was used for all assays.

\section{Determination of CAT, GST and GSH in plasma and red blood cells}

CAT activity was assayed according to the method of Claiborne ${ }^{[16]}$ by monitoring the disappearance of $\mathrm{H}_{2} \mathrm{O}_{2}$ at $240 \mathrm{~nm}$ while GST activitywas determined at $340 \mathrm{~nm}$ by measuring the formation of the 1-chloro-2, 4-dinitrobenzene and GSH conjugate at $25^{\circ} \mathrm{C}$, pH 7.0. ${ }^{[17]}$ GSH was determined according to the method of Ellman. ${ }^{[18]}$

\section{Statistical protocol}

All data were expressed as mean \pm S.D. and were analyzed using Winstat 2.0 (Kalmia Co. Inc., Cambridge, U.S.A.). Comparisons among the groups were assessed by one way analysis of variance (ANOVA) followed by the Least Significant Difference test (LSD test). Correlations were calculated by Pearson's method and $\mathrm{P}$ values $<0.05$ were considered statistically significant.

\section{RESULTS}

Some demographic and clinical characteristics of the subjects are depicted in Table 2 . In both malaria and typhoid + malaria subjects, the highest parasite 
O. Ademuyiwa, et al.: Endogenous antioxidant defenses in malaria comorbidly occurring with typhoid

Table 2 Clinical characteristics and antioxidant responses of the subjects

\begin{tabular}{|c|c|c|c|c|c|c|c|c|}
\hline \multirow{2}{*}{$\begin{array}{l}\text { Subject / } \\
\text { Parameters }\end{array}$} & \multicolumn{2}{|c|}{ Control } & \multicolumn{2}{|c|}{ Malaria } & \multicolumn{2}{|c|}{ Typhoid } & \multicolumn{2}{|c|}{ Typhoid + Malaria } \\
\hline & Male & Female & Male & Female & Male & Female & Male & Female \\
\hline Age (years) & $33.19 \pm 6.32$ & $32.44 \pm 5.78$ & $28.19 \pm 11.12$ & $26.64 \pm 7.68$ & $30.10 \pm 9.50$ & $34.18 \pm 5.89$ & $31.41 \pm 10.87$ & $29.70 \pm 8.31$ \\
\hline PCV & $44.00 \pm 0.95^{a}$ & $39.58 \pm 0.79^{b}$ & $33.06 \pm 4.99^{c}$ & $29.50 \pm 3.41^{d}$ & $39.00 \pm 2.11^{b}$ & $38.40 \pm 1.34^{b}$ & $33.35 \pm 4.44^{c}$ & $32.10 \pm 3.81^{c}$ \\
\hline $\begin{array}{l}\text { Parasite } \\
\text { density }\end{array}$ & $0^{\mathrm{a}}$ & $0^{\mathrm{a}}$ & $7250.00 \pm 1437.59^{b}$ & $8863.64 \pm 2082.71^{c}$ & $0^{\mathrm{a}}$ & $0^{\mathrm{a}}$ & $7088.24 \pm 939.34^{b}$ & $7900.00 \pm 966.09^{b}$ \\
\hline $\begin{array}{l}\text { RBC GSH } \\
(\mathrm{mM})\end{array}$ & $10.72 \pm 3.14^{\mathrm{a}}$ & $9.45 \pm 0.99^{b}$ & $6.63 \pm 1.76^{d}$ & $6.31 \pm 2.83^{d}$ & $8.21 \pm 3.34^{c}$ & $7.29 \pm 1.91^{\mathrm{d}}$ & $6.19 \pm 2.50^{d}$ & $7.69 \pm 2.05^{d}$ \\
\hline $\begin{array}{l}\text { Plasma GSH } \\
(\mathrm{mM})\end{array}$ & $1.20 \pm 0.23^{a}$ & $1.08 \pm 0.06^{a}$ & $2.00 \pm 0.72^{\mathrm{c}}$ & $1.98 \pm 0.95^{c}$ & $1.62 \pm 0.63^{b}$ & $1.34 \pm 0.33^{a}$ & $2.17 \pm 1.21^{d}$ & $2.05 \pm 0.71^{\mathrm{c}}$ \\
\hline $\begin{array}{l}\text { RBC CAT } \\
\text { (units/ml) }\end{array}$ & $887.68 \pm 136.12^{a}$ & $857.76 \pm 100.12^{a}$ & $1989.57 \pm 998.87^{b}$ & $2276.82 \pm 1035.53^{b}$ & $3123.24 \pm 796.98^{c}$ & $2013.76 \pm 279.06^{b}$ & $2119.22 \pm 1139.49^{b}$ & $2304.61 \pm 1058.77^{b}$ \\
\hline $\begin{array}{l}\text { Plasma CAT } \\
\text { (units/ml) }\end{array}$ & $7.08 \pm 1.75^{a}$ & $5.72 \pm 0.23^{a}$ & $44.21 \pm 20.59^{c}$ & $31.46 \pm 13.98^{b}$ & $45.33 \pm 20.33^{c}$ & $50.96 \pm 10.79^{d}$ & $39.25 \pm 17.13^{b}$ & $31.49 \pm 12.30^{\mathrm{b}}$ \\
\hline $\begin{array}{l}\text { RBC GST } \\
\text { ( } \mu \mathrm{mol} \text { product/ } \\
\mathrm{min} / \mathrm{ml})\end{array}$ & $0.97 \pm 0.23^{a}$ & $0.99 \pm 0.11^{a}$ & $0.95 \pm 0.14^{a}$ & $0.97 \pm 0.25^{\mathrm{a}}$ & $0.78 \pm 0.25^{b}$ & $0.66 \pm 0.39^{b}$ & $1.04 \pm 0.28^{c}$ & $1.30 \pm 1.04^{d}$ \\
\hline $\begin{array}{l}\text { Plasma GST } \\
\times 10^{-3}(\mu \mathrm{mol} \\
\text { product/ } \\
\mathrm{min} / \mathrm{ml})\end{array}$ & $5.22 \pm 0.67^{a}$ & $5.23 \pm 0.74^{a}$ & $4.75 \pm 2.91^{a}$ & $5.82 \pm 3.41^{a}$ & $4.89 \pm 3.37^{a}$ & $8.74 \pm 6.01^{b}$ & $5.27 \pm 2.75^{a}$ & $4.47 \pm 2.29^{a}$ \\
\hline
\end{tabular}

density was observed in the female subjects. In typhoid fever positive subjects (typhoid alone and typhoid + malaria), the antibody titer values in both males and females ranged from 1: 80 to 1: 320 . However, the frequency of high titer values was more in female subjects than male subjects. While no significant difference was observed in the mean packed cell volume (PCV) values of female typhoid subjects when compared with their control counterparts $(\mathrm{P}>0.05), \mathrm{PCV}$ values of other parasite-infected subjects decreased significantly when compared with control $(\mathrm{P}<0.05)$. The decrease was more marked in malaria-infected females when compared with control and other parasite-infected subjects. Quantitatively, PCV values of the parasite-infected subjects were between 20 and $25 \%$ lower than their control counterparts.

The mean values of the investigated antioxidant profiles in the plasma and erythrocytes of the subjects are also depicted in Table 2. The presence of either or both parasitic infections resulted in significant alterations in the antioxidant responses of the subjects $(\mathrm{P}<0.05)$. In the plasma and erythrocytes of the parasite-infected subjects, there was a significant increase in the activity of CAT $(\mathrm{P}<0.05)$. In the erythrocyte of these subjects, the activity of CAT was between 2.24 and 3.50 times higher than that of the control, with the highest activity observed in typhoidinfected male subjects. In the plasma of parasite-infected subjects, CAT activity was between 5.5 and 8.9 times higher than control subjects, with the highest activity observed in typhoid-infected females. In contrast to CAT, GST activities in both plasma and erythrocytes of the subjects responded differently to the presence of either or both parasitic infections. While erythrocyte GST activity in malaria infection was not significantly different from control $(\mathrm{P}>0.05)$, GST activity was reduced in both sexes in typhoid infection $(\mathrm{P}<0.05)$, whereas it increased when both typhoid and malaria infections were present $(\mathrm{P}<0.05)$. The increase was more marked in the females than males. With the exception of female typhoid subjects where a significant increase was observed in plasma GST activity $(\mathrm{P}<0.05)$, plasma GST activity in other parasite-infected subjects was not significantly different from controls $(\mathrm{P}>0.05)$.

The concentrations of the non-enzymic antioxidant glutathione (GSH) in the plasma and erythrocytes of the subjects are also depicted in Table 2. While the erythrocytes responded to the presence of parasitic infections with a decrease in GSH concentrations $(\mathrm{P}<0.05)$, the plasma seems to respond with an increase in this non-enzymic antioxidant $(\mathrm{P}<0.05)$. The decrease in erythrocyte GSH was more marked in males infected with both parasites. With a few exceptions, antioxidant responses of the females to the presence of either or both parasitic infections seem to be lower than that of their male counterparts.

Correlations, as calculated by the Pearson's method, revealed significant direct linear and inverse linear relationships among the parameters (Tables 3 and 4). While parasite density correlated positively with plasma GSH, significant negative correlations were observed between parasite density and PCV; and parasite density and erythrocyte GSH $(\mathrm{P}<0.05)$. PCV also correlated positively with erythrocyte GSH (Table 3), whereas negative correlations were observed between PCV and erythrocyte 
O. Ademuyiwa, et al.: Endogenous antioxidant defenses in malaria comorbidly occurring with typhoid

Table 3 Positive correlations among parameters in the subjects

\begin{tabular}{lcc}
\hline Parameter & $\begin{array}{c}\text { Correlation } \\
\text { coefficient }(\mathbf{r})\end{array}$ & P value \\
\hline Parasite density vs Plasma GSH & 0.444 & $5 \times 10^{-8}$ \\
Plasma GSH vs RBC CAT & 0.305 & $2 \times 10^{-4}$ \\
Plasma CAT vs RBC CAT & 0.481 & $1 \times 10^{-9}$ \\
PCV vs RBC GSH & 0.348 & $2 \times 10^{-4}$ \\
\hline
\end{tabular}

Table 4 Negative correlations among parameters in the subjects

\begin{tabular}{lcc}
\hline Parameter & $\begin{array}{c}\text { Correlation } \\
\text { coefficient }(\boldsymbol{r})\end{array}$ & P value \\
\hline Parasite density vs PCV & -0.850 & $1 \times 10^{-30}$ \\
Parasite density vs RBC GSH & -0.327 & $6 \times 10^{-5}$ \\
RBC CAT vs PCV & -0.379 & $4 \times 10^{-5}$ \\
RBC CAT vs RBC GSH & -0.270 & $9 \times 10^{-4}$ \\
Plasma CAT vs PCV & -0.221 & 0.012 \\
Plasma GSH vs PCV & -0.385 & $3 \times 10^{-5}$ \\
Plasma GSH vs RBC GSH & -0.326 & $7 \times 10^{-5}$ \\
\hline
\end{tabular}

CAT, and plasma GSH (Table 4). While erythrocyte CAT correlated positively with plasma GSH, a negative correlation was observed between erythrocyte CAT and erythrocyte GSH.

\section{DISCUSSION}

Oxidative stress appears to be an important factor in the pathophysiology of many human diseases. ${ }^{[19]}$ Oxidative stress may result in damage to critical macromolecules including DNA, lipids and proteins. ${ }^{[20]}$ In order to cope with this oxidative insult, cells have a defense system consisting of antioxidant enzymes (catalase CAT, superoxide dismutase SOD, glutathione peroxidase GP, glutathione transferase GST) and antioxidant molecules (glutathione GSH, ascorbic acid and vitamin E) among others that can terminate the oxygen radical cascade and render the toxic metabolites innocuous. ${ }^{[2]}$ Measurement of these antioxidants is therefore an indirect and non-invasive test that could be used to assess the induction of oxidative stress in a cell. In this study, we explored the role of three of these antioxidants (CAT, GST and GSH) as biological markers of oxidative stress in malaria, typhoid and typhoid + malaria infections.

The results of this present study indicate that acute malaria, typhoid and typhoid + malarial infections are accompanied by significant alterations in the antioxidant defense system of the host thus suggesting induction of oxidative stress. The major characteristics of these alterations are depletion of erythrocyte GSH, increase in plasma GSH and increase in erythrocyte and plasma CAT activity. Our observation of decreased erythrocyte GSH in malaria patients agrees with the observations of other workers. ${ }^{[22,23]}$ We were unable to locate any data in the literature with which to compare the antioxidant response in typhoid and typhoid + malaria infections. Our findings however indicate that comparatively, the antioxidant response in malaria infection alone and typhoid + malarial infections seem to share some common denominators (Table 2).

In addition to these similarities, our findings further revealed some striking differences in the pattern of antioxidant response induced in the host by the presence of either or both parasitic infections. While depletion of erythrocyte GSH, increase in plasma GSH and increase in the expression of CAT in both plasma and erythrocyte seem to characterize the parasitic infections, depletion of erythrocyte GSH and increase in plasma GSH are less well pronounced in typhoid infection than malaria or typhoid + malaria infections. In addition, even though the presence of either or both parasitic infections resulted in increased expression of CAT in both plasma and erythrocyte, the highest CAT activity in both compartments of the blood was observed in typhoid infection. While the highest erythrocyte CAT activity was observed in typhoid-infected males, the highest plasma CAT activity was observed in females infected with typhoid. Furthermore, while sex difference was not apparent in the other investigated antioxidants in malaria and typhoid + malarial infections, sex differences were observed in the antioxidant profiles in typhoid infection. These observations suggest that the antioxidant response in typhoid infection differs markedly from that of malaria and that the sex of patient might influence this antioxidant response. In their study of 102 typhoid subjects, Khan and his colleagues ${ }^{[24]}$ determined serum activities of aspartate transaminase (AST), gammaglutamyltransferase (GGT), as well as the concentration of bilirubin in male and female subjects. Increased activities of these enzymes and a high concentration of bilirubin were observed in the female subjects when compared with their male counterparts, thus indicating sex differences in these parameters in typhoid infection. In addition, the severity of the disease was more pronounced in women than in men. This observation, together with the findings of this present study suggest that in typhoid infection, the sex of the patient might influence not only the antioxidant response, but also other clinical parameters as well.

The roles of antioxidants and oxidative stress in the pathogenesis of malaria and typhoid infections, together with sex differences observed in the antioxidant response in 


\section{O. Ademuyiwa, et al.: Endogenous antioxidant defenses in malaria comorbidly occurring with typhoid}

typhoid infections are still unknown. While clinical observations and experimental evidence indicate that oxidative stress in malaria results from intra-erythrocytic parasite's metabolic processes ${ }^{[1,25]}$ and host immune reaction as an acute phase response ${ }^{[1]}$ the mechanisms underlying oxidative stress induced by typhoid infection remain to be elucidated. The reduced concentration of GSH and activity of GST observed in typhoid-infected subjects when compared with their malaria counterparts (who in spite of the reduced concentrations of GSH, had GST activity not significantly different from control), suggest a different pattern of induction of oxidative stress. Furthermore, while the increase in plasma CAT in malaria and malaria + typhoid subjects might be attributed to release of the enzyme from red blood cells due to hemolysis, the same cannot be said of overexpression of plasma CAT in typhoid subjects since the PCV observed in them compared favourably with PCV of control subjects. All these observations suggest that other mechanisms might be responsible for the over-expression of CAT in typhoid infection.

In typhoid infection, the primary sites of location of S. typhi within the liver are the Kupffer cells. ${ }^{[24,26]}$ The specific response of Kupffer cells to foreign particulate material is well known and several toxins, as well as physiological substances, have been shown to have effects on these cells. ${ }^{[27,28]}$ In women, hormones, most especially estrogen, might influence the course of typhoid infection. ${ }^{[2]}$ Estrogens are known to activate Kupffer cells, resulting in the production of ROS. ${ }^{[27,28]}$ Estrogens are also known to form conjugates with GSH, thus further depleting the body stores of this antioxidant. ${ }^{[29]}$ Although the levels of estrogen were not determined in this study, majority of the women who participated in this study were women in their reproductive age. The decreased activity of RBC GST and the depletion of RBC GSH in the typhoid-infected women suggest higher circulating levels of molecules requiring conjugation. ROS can cause hepatic injury resulting in a decrease in the endotoxin-removing activity of Kupffer cells. ${ }^{[28]}$ The observation of increased activities of GGT and AST, together with the increased serum concentrations of bilirubin, ${ }^{[2]}$ suggest that typhoid infection in women of reproductive age might be accompanied by a transient hepatic injury which eventually might influence the response of the women to typhoid infection. Men on the other hand may have greater opportunities of acquiring $S$. typhi than women because of the extra care taken by women in the preparation of food and the indiscriminate eating habits of men at road side locations. ${ }^{[24,30,31]}$ Repeated exposure to $S$. typhi may provide men with a strong local mucosal immunity including strong local $\operatorname{IgA}$ response associated with the appearance of circulating $\operatorname{IgA}{ }^{[32]}$ Part of this immunity could also be an over-expression of CAT in erythrocytes of men compared to women. This in turn may translate into milder disease in men. ${ }^{[24]}$

We conclude from our findings that over-expression of CAT in plasma and erythrocytes of typhoid subjects, together with alterations observed in other antioxidants, were adaptive responses on the part of the subjects to protect against oxidative insult as a result of $S$. typhi invasion. Furthermore, the sex differences observed in the antioxidant response in typhoid infection in this study are disease-related phenomena and might be due to differences in immune response between the male and the female. In further longitudinal studies that we are pursuing in this laboratory, the levels of estrogen and endotoxin will be determined, together with the rate of efflux of GSH-conjugated products. These will further be compared with male and female subjects below age 12 years. The results of these studies should contribute to a better understanding of the mechanisms underlying the sex differences observed in the antioxidant response in typhoid infection.

\section{ACKNOWLEDGEMENTS}

The authors are grateful to the authority of the Federal Medical Centre, Abeokuta, Nigeria and the patients who participated in the study. The technical assistance of Mrs. J. O. Adebawa is also gratefully acknowledged.

\section{REFERENCES}

1. Becker K, Tilley L, Vennerstrom JL, Roberts D, Rogerson S, Ginsburg H. Oxidative stress in malaria parasite-infected erythrocytes: host-parasite interactions. Int J Parasitol 2004; 34:163-89.

2. Monti D, Basilico N, Parapini S, Pasini E, Olliaro P, Taramelli D. Does chloroquine really act through oxidative stress? Fed Eur Biochem Soc Lett 2002; 522:3-5.

3. Murphy SC, Breman JG. Gaps in the childhood malaria burden in Africa: cerebral malaria, neurological sequelae, anemia, and respiratory distress, hypoglycemia, and complications of pregnancy. Am J Trop Med Hyg 2001; 64(Suppl):57-67.

4. Brenner FW, Villar RG, Angulo FJ, Tauxe R, Swaminathan B. Salmonella nomenclature. J Clin Microbiol 2000; 38:2465-7.

5. WHO. The World Health Report 1996: Fighting Disease, Fostering Development. World Health Organisation, Geneva 1996.

6. Ojo DA, Mafiana CF. Evaluation of fever in the presumptive diagnosis of malaria and typhoid infections in an area of high malaria endemicity. Nig J Parasitol 2001; 22(1\&2)35-42.

7. Atamna $\mathrm{H}$, Ginsburg $\mathrm{H}$. Origin of reactive oxygen species in erythrocytes infected with Plasmodium Falciparum. Mol Biochem Parasitol 1993; 61:231-41.

8. Campanale N, Nickel C, Daubenberger CA, Wehlan DA, Gorman JJ Klonis N, Becker K, Tilley L. Identification and characterization of hemeinteracting proteins in the malaria parasite, Plasmodium falciparum. J Biol Chem 2003; 278(30):27354-61. 


\section{O. Ademuyiwa, et al.: Endogenous antioxidant defenses in malaria comorbidly occurring with typhoid}

9. Hunt $\mathrm{NH}$, Stocker R. Oxidative stress and the redox status of malariainfected erythrocytes. Blood Cells 1990; 16:499-530.

10. Kirk . Membrane transport in the malaria-infected erythrocyte. Physiol Rev 2001; 81(2);495-537.

11. WHO. Malaria diagnosis: New perspectives. Report of a Joint/USAID Informal Consultation. 25-27 October 1999, WHO/MAL/2000, 1091; 2000.

12. Rogerson SJ, Chaluluka E, Kanjala M, Mkundika P, Mhango C, Molyneux ME. Intermittent sulfadoxine-pyrimethamine in pregnancy: effectiveness against malaria morbidity in Blantyre, Malawi, in 1997-99. Trans R Soc Trop Med Hyg 2000; 94:549-53.

13. FAO/WHO. Joint FAO/WHO Expert Committee on Brucellosis. World Health Organization Technical Report Series 1958; 148:1.

14. Felix A. Technique and interpretation of the Weil-Felix test in typhus fever. Trans R Soc Trop Med Hyg 1944; 37:321.

15. Felix A. Standardization of diagnostic agglutination tests; typhoid \& paratyphoid A \& B fevers. Bull World Health Org 1950; 2(4):643-9.

16. Claiborne A. Catalase activity. In: Greenwald RA, (Ed). CRC Handbook of Methods for Oxygen Radical Research. 1986; CRC Press Inc., Florida, FL, pp. 283-4.

17. Habig WH, Jakoby WB. Glutathione-S-transferase in rat and human. Methods Enzymol 1981; 77:218-31.

18. Ellman GL. Tissue sulphydryl groups. Arch Biochem Biophys 1959; 82:70-7.

19. Halliwell B, Gutteridge JMC, Cross CE. Free radicals, antioxidants, and human disease: Where are we now? J Lab Clin Med 1992; 119:598-620.

20. Klaunig JM, Xu Y, Isenberg JS, Bachowski S, Kolaja KL, Jiang JZ, Stevenson DE. The role of antioxidative stress in chemical carcinogenesis. Environ Health Perspect 1998; 106(suppl. 1):289-95.

21. Lopez-Helin J, Garcia-Arumi E, Schwartz S. Oxidative stress induces age-dependent changes in lymphocyte protein synthesis and second messenger levels. Life Sci 1998; 63(1):13-21.

22. Das BS, Nanda NK. Evidence for erythrocytes lipid peroxidation in acute falciparum malaria. Trans R Soc Trop Med Hyg 1999; 93:58-62.
23. Lüersen K, Walter RD, Müller S. Plasmodium falciparum-infected red blood cells depend on a functional glutathione de novo synthesis attributable to an enhanced loss of glutathione. Biochem J 2000; 346:545-52.

24. Khan M, Coovadia VM, Connoly C, Sturm AW. Influence of sex on clinical features, laboratory findings, and complications of typhoid fever. Am J Trop Med Hyg 1999; 61(1):41-6.

25. Tilley L, Loria P, Foley M. In: Totowa RPJ. (Ed.), Choloroquine and other quinoline antimalarials. Antimalarial Chemotherapy. Humana Press, Totowa, NJ 2001; pp. 87-122.

26. Swanson RN, O'Brien AD. Genetic control of the innate resistance of mice to Salmonella typhimurium: Ity gene is expressed in vivo 24 hours after infection. J Immunol 1983; 131:3014-19.

27. Arthur MJP, Kowalski-Saunder P, Wright R. Corynebacterium parvumelicited hepatic macrophages demonstrate enhanced respiratory burst activity compared with resident Kupffer cells in the rat. Gastroenterol 1986; 91:174-81.

28. Cattley RC, Popp JA. Liver. In: Haschek WM, Rosusseaux CG, Wallig MA.(Eds.), Handbook of Toxicologic Pathology, $2^{\text {nd }}$ Ed. 2002; vol. 2 , Academic Press, San Diego, CL, pp. 187-225.

29. Meister A. Glutathione deficiency produced by inhibition of its synthesis, and its reversal; applications in research and therapy. Pharmacol Ther 1991; 51:155-94

30. Basten JPV, Stockenbrugger R. Typhoid perforation: a review of the literature since 1960. Trop Geogr Med 1994; 46:336-9.

31. Vollaard AM, Ali S, van Asten HAGH, Widjaja S, Visser LG, Surjadi C, van Dissel JT. Risk factors for typhoid and paratyphoid fever in Jakarta, Indonesia. JAMA 2004; 291(21):2607-15.

32. Mattingly JA, Waksman BH. Immunologic suppression after oral administration of antigen. I. Specific suppressor cells formed in rat Peyer's patches after oral administration of sheep erythrocytes and their systemic migration. J Immunol 1978; 121:1878-83. 